\title{
Investigation of Brucella seroprevalence in human and livestocks in Igdır, Turkey
}

\author{
Gülhan Bora ${ }^{1, *}$, Yasemin Akkoyunlư ${ }^{2}$, Mehmet Berköz ${ }^{3}$, Güneş Açıkgöz ${ }^{4}$, \\ Mustafa Berktaş ${ }^{5}$, Fikret Altındağ ${ }^{6}$, Aydoğan Bora ${ }^{1}$ \\ ${ }^{1}$ Yuгuncu Yal University, Faculty of Pharmacy, Department of Pharmaceutical Microbiology, Van, Turkey \\ ${ }^{2}$ Bezmialem Vakerf University, Faculty of Medicine, Department of Infectious Diseases and Clinical Microbiology, \\ Istanbul, Turkey \\ ${ }^{3} Y$ uұuncu Yal University, Faculty of Pharmacy, Department of Pharmaceutical Biotechnology, Van, Turkey \\ ${ }^{4}$ Mustafa Kemal University, Vocational School of Health Services, Hatay, Turkey \\ ${ }^{5}$ Yuzuncu Yol University, Faculty of Medicine, Department of Microbiology, Van, Turkey \\ ${ }^{6}$ Igdir University, Medical Technology Vocational Training School, Department of Clinical Microbiology, Igdir, Turkey
}

\begin{abstract}
Brucellosis is a zoonotic disease of worldwide and still remains endemic in some developing countries, especially in Turkey. Milk is the main food product serving as a vector for Brucella. In this study we aimed to investigate the seroprevalence of human and animal brucellosis. The study group consisted of 358 subjects who had high risk occupations of animal breeder and farmer. The test results were interpreted and titers equal or in excess of $1 / 40$ were considered significant. 189 farm animals were incorporated to our research. Among these animals, 104 of them were sheep and goat and 85 of them were cattle. The Brucellosis Milk Ring Test was used to test raw milk samples collected the selected herds in the study area. The seroprevalence of human brucellosis was $6.7 \%$. Seroprevalence of animal brucellosis was found as $22.75 \%$ in livestocks. This study is important for being the first study in recent years that demonstrates the Brucella seropositivity rates in Igdır Province. This high seropositivity in our region may depend on the high rates of animal brucellosis; those of which were inadequate under control by veterinary and by vaccination and people who consume the milk by without boiling.
\end{abstract}

Key Words: Brucellosis, seroprevalence, vaccination, livestocks

\section{Introduction}

Brucellosis is a zoonotic disease with a global distribution caused by bacteria of the genus Brucella. Major efforts have been undertaken around the world to control brucellosis due the significant economic losses associated with the occurrence of the disease in domestic livestock and the often debilitating disease associated with human infection (1). Clinical signs of brucellosis in domestic livestock include late-term abortions, decreased milk production and lowered fertility in both males and females. The disease in humans is associated with a number of nonspecific complaints including irregular or intermittent fevers, night sweats and headaches. Untreated brucellosis in humans can lead to chronic osteoarticular complications manifesting as joint pain, joint effusion and debilitating arthritis (2). Particular biovars of Brucella melitensis are associated with pathogenicity in different domestic animals. B. abortus is the biovar most commonly associated with brucellosis disease in cattle (3).

Brucellosis in humans is considered as a food borne disease or a disease related to occupational exposures (4). The routes of infection for humans are similar to those for animals: ingestion, inhalation, or through direct contact of the organism with a break in the skin. The key feature of brucellosis as a zoonosis is that it is a pure zoonosis: a disease transferred only from animals to people. Human-to-human transmission has occurred, but is exceedingly rare (5). The Brucella spp. and their biovars have different zoonotic potential. B. ovis and B. suis biovars two, four and five have essentially no zoonotic potential. B. canis, B. abortus biovar five and B. neotomae have very low zoonotic risk, but all other biovars of $B$. melitensis, B. abortus and B. suis can cause illness in humans $(5,6)$.

*Corresponding Author: Dr. Gülhan Bora, Yuzuncu Yil University, Faculty of Pharmacy, Department of Pharmaceutical Microbiology, Van, TURKEY, Tel: +90 (432) 22510 24, Fax: +90(432)21675 19, E-mail: gulhanarvas@yahoo.com-gunesani@hotmail.com

Received: 13.06 .2016 , Accepted: 16.11 .2016 
Food borne illness is contracted through the consumption of raw milk or raw milk dairy products. Meat products are not considered high risk and the actual risk is likely negligible. The one exception is with pork meat products $(7,8)$. Bacteremia in swine results in disseminated infection rather than an infection localized to the reticulo-endothelial system and reproductive tract; as a result there can be a substantial number of bacteria in the muscle tissue. In addition, the consumption of organ meats poses a risk. The control of animal brucellosis is very important for the prevention of human infection $(9,10)$. Also important in the prevention of human infection is the use of pasteurized milk and milk products in developing countries $(9,11)$.

Brucellosis is still endemic in many regions of the world, although it has been successfully eradicated in some countries $(12,13)$. The infection threatens both domesticated animal and human health and causes considerable economic losses. It is especially widespread in South Europe, North Africa, Middle East and Near East (12-14).

In the Near East region countries, social and economic factors play a major role in the spread of brucellosis $(15,16)$. Turkey is considered to be endemic for brucellosis, although little information is available; previous studies are limited to food-producing animals such as cattle and ewes and reports of human brucellosis in Turkey are limited to a few cases (17).

Turkey occupies a unique geographical, cultural and economic position at the crossroads between Europe and Asia. It is surrounded by the Black Sea in the north, the Mediterranean Sea in the south, and the Aegean Sea in the west. It shares land boundaries with Greece and Bulgaria in the northwest, Georgia, Armenia and Nakhchivan in the northeast, Iran in the east, and Iraq and Syria in the southeast (18).
The geographic situation of Turkey is always a risk factor for the dissemination of contagious diseases, mainly from the eastern and southeastern neighbors (17). I ğdır province is one of the most important city in this region and located in a strategic area that has border to three cousin the border of three country (Nakhichevan, Armenia and Iran) (Figure 1).

In this study we aimed to investigate the seroprevalence of human and animal brucellosis in Iğdır province, North-east Anatolia. Since there is scarce information on the epidemiology of brucellosis in Iğdır province, particularly in those whose job put them at risk of contracting the disease, this study was conducted to determine the risk of exposure to Brucella in people who have direct contact with livestock as a consequence of their job (19). We also tried to elucidate the correlation between consumption of dairy products and seropositivity for Brucella.

\section{Material and methods}

This study was conducted in Igdir province, districts and neighboring districts of Igdir between June 2012 and October 2012. Iğdır and the surrounding regions were divided into the certain regions, as Igdir Center, Aralık, Tuzluca, Doğubeyazıt, Karakoyunlu and Kağızman. The study group consisted of 358 subjects who had high risk occupations of animal breeder and farmer, living in the randomly selected villages from these regions. The ethical approval was taken from the local committee. The study group consisted of 78 male $(21.79 \%)$ and 280 female $(78.21 \%)$, with a median age $48.67 \pm 19.09$ years, ranging between 33-71 years.

Researchers in this study interviewed the subjects using a standard form. Questions included breeder name and surname, date, education, age, gender

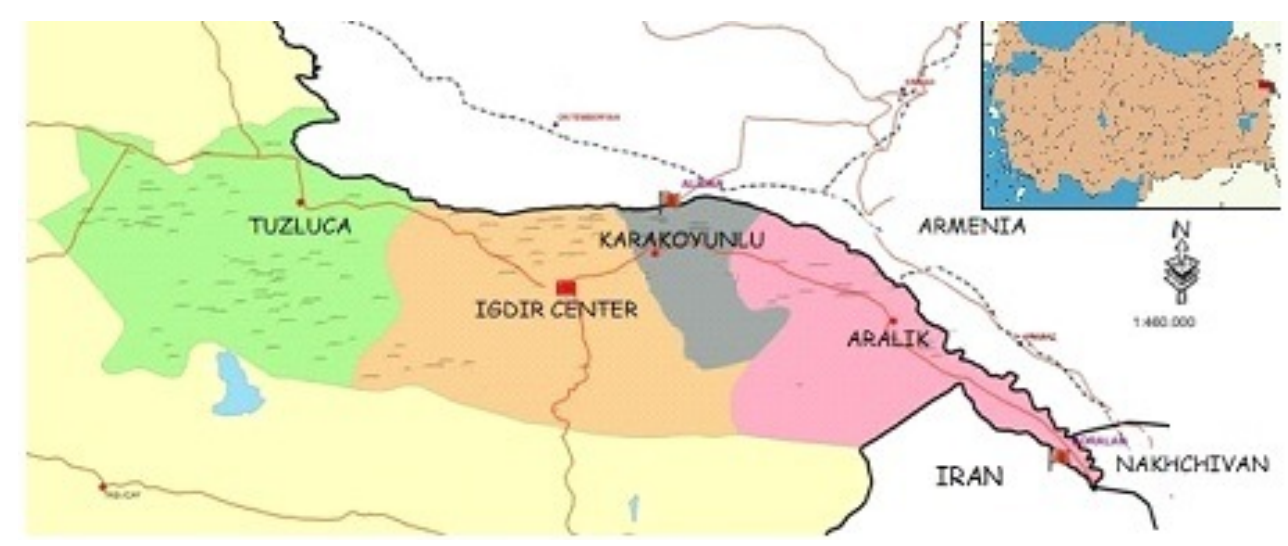

Fig. 1. Map of Turkey and geographical location of Igdır Province.

East J Med Volume:21, Number:3, July-September/2016 
and number of cattle, sheep and/or goat and their races.

Prevalence of brucella-specific antibodies was investigated in sera of the subject. Firstly, blood samples collected from all subjects were centrifuged at $1200 \mathrm{~g}$ for 5 minutes at $+4^{\circ} \mathrm{C}$. Serum samples were harvested and kept at $-20^{\circ} \mathrm{C}$ until used. Serum tube agglutination test including Coombs reactive was performed with commercial Brucella antigen according to the manufacturer's instructions $(20,21)$. The test results were interpreted and titers equal or in excess of $1 / 40$ were considered significant.

In the second part of this study, we collected milk samples from the farm animals that were breed by the farmers for reveal of brucellosis. For this purpose, 189 farm animals were incorporated to our research. Animals were separated as dairy cattle, sheep and goat and milk analysis was performed from the herds. Among these animals, 104 of them were sheep and goat and 85 of them were cattle. Milk analysis of sheep and goats were performed with the aid of selecting in $1 / 10$ ratio from the single race animal herds and in $1 / 5$ ratio from the different race animal herds by the method of randomize sampling. In the same way, milk analysis of cattles were performed with the aid of selecting in $1 / 5$ ratio from the domestic and culture race animal herds.

Milk samples were collected soon after the morning or evening milking had been completed. Individual cattle were routinely milked into buckets that were then emptied into aluminum milk cans or an equivalent small bulk storage container. The milk samples were tested for the presence of Brucella antibodies using standard $B$. abortus strain 1119-3 Brucellosis Milk Ring Test antigen provided by the Pendik Veterinary Control Institute, Istanbul, Turkey.

One $\mathrm{ml}$ of whole milk from each sample was transferred to a narrow, sterile plastic test tube.
BRT antigen $(0.03 \mathrm{ml})$ was added to each of the samples and mixed well. The milk samples were then incubated for 1 hour at $37^{\circ} \mathrm{C}$ in a portable incubator powered by a 12 -volt car battery. Concentration of dyed antigen in the cream layer, forming a dark blue ring, indicated a positive reaction. Results were read at the conclusion of incubation and recorded.

Data were coded and analyzed by SPSS for Windows. Categorical variables were analyzed by $\chi^{2}$ or Fisher exact test when appropriate. $\mathrm{p}$ value $<0.05$ was considered statistically significant.

\section{Results}

Totally 358 individual who had high risk occupations of animal breeder and farmer in Igdir province and its surrounding regions were included to our study. This study was arranged in Igdir Center, Aralık, Tuzluca, Doğubeyazıt, Karakoyunlu and Kağ1zman and from these regions, 36, 55, 45, 118, 18 and 86 subjects were admitted to our study, respectively.

The seroprevalence of Brucella specific antibodies were based on titers of $1 / 40$ by Serum tube agglutination test including Coombs reactive. The seroprevalence of human brucellosis was 6.7\% in our study (positive in 24 subjects). Samples of 334 subjects $(93.3 \%)$ resulted negative in the agglutination test. Seroprevalence of Brucella antibodies were listed in Table 1 according to the subjects' location and antibody titers.

Seroprevalence of Brucellosis was found as $11.5 \%$ in male subjects ( 9 of 78 individuals) and $5.4 \%$ in female subjects (15 of 280 individuals). According to this data, there were no significant differences between the genders $(p>0.05)$. Seroprevalence of Brucella antibodies were listed in Table 2 according to the subjects' gender.

Table 1. Seroprevalence of Brucella antibodies according to the subjects' location and antibody titers

\begin{tabular}{lcccccc}
\hline & $\begin{array}{c}1 / 40 \\
(\mathrm{n})\end{array}$ & $\begin{array}{c}1 / 80 \\
(\mathrm{n})\end{array}$ & $\begin{array}{c}1 / 160 \\
(\mathrm{n})\end{array}$ & $\begin{array}{c}1 / 320 \\
(\mathrm{n})\end{array}$ & $\begin{array}{c}\text { Total } \\
(\mathrm{n})\end{array}$ & $\begin{array}{c}\text { (n) } \\
(\mathrm{n})\end{array}$ \\
\hline Aralık & - & 1 & 1 & - & - & 2 \\
Tuzluca & - & - & - & - & - & 18 \\
Doğubeyazıt & 5 & 4 & 4 & - & - & - \\
Karakoyunlu & - & - & - & - & - & 3 \\
Kağ1zman & - & 1 & - & - & - & 3 \\
Iğdır Center & 1 & 2 & - & 4 & 1 & 24 \\
\hline Total & 6 & 8 & 5 & - & - & - \\
\hline
\end{tabular}

( $\mathrm{n}=$ number of individuals) 
Table 2. Seroprevalence of Brucella antibodies according to the subjects' gender

\begin{tabular}{lcccc}
\hline & $\begin{array}{c}\text { Male } \\
(\mathrm{n})(\%)\end{array}$ & $\begin{array}{c}\text { Female } \\
(\mathrm{n})(\%)\end{array}$ & $\begin{array}{c}\text { Total } \\
(\mathrm{n})(\%)\end{array}$ & $\mathrm{p}$ value \\
\cline { 1 - 4 } Positive & $9(11.5 \%)$ & $15(5.4 \%)$ & $24(6.7 \%)$ & \\
Negative & $69(88.5 \%)$ & $265(94.6 \%)$ & $334(93.3 \%)$ & $\mathrm{p}=0.054$ \\
\cline { 1 - 4 } Total & $78(100 \%)$ & $280(100 \%)$ & $358(100 \%)$ & \\
\hline
\end{tabular}

( $\mathrm{n}=$ number of individuals)

Totally 189 livestocks in Igdir province and its surrounding regions were included to our study. Seroprevalence of Brucellosis was found as $22.75 \%$ in livestocks (43 of 189 animals). Seroprevalence of Brucella antibodies according to the livestocks' location and antibody titers was shown in Table 3.

Seroprevalence of Brucellosis was found as $26.92 \%$ in sheep and goat and $17.65 \%$ in cattle. Seroprevalence of Brucella antibodies according to the livestocks' species and location was shown in Table 4. Seroprevalence of Brucellosis in sheeps and goats was 1.53 fold higher than the cattles. A significantly higher seroprevalence of brucellosis among sheeps and goats compared to the cattles was found $(\mathrm{p}<0.05)$.

\section{Discussion}

The geographic position of Turkey is always a risk factor for the dissemination of infectious diseases, especially from the eastern and southeastern neighbors. Brucellosis is endemic in all of the countries around Turkey, especially in Iran, Iraq and Syria (22). In Iran, the prevalence of brucellosis among sheep and goats was $10.2 \%$ and among cattles were $17.5 \%$ in the 1990 s. In Iran, also, human brucellosis is a serious public health problem, with almost 240 cases per million (23). In Iraq, the seroprevalence among sheep and goats was $15 \%$ and among investigated cattle was $3 \%$, with approximately 280 human cases per million. Syria has the world's highest reported incidence of human brucellosis, with over than 1600 cases per million (24).

In Turkey, the reported incidence was over 18000 cases in 2004, although, incidence of brucellosis was only 37 cases in 1970s (25). Probably, this significant increase reflects improvements in diagnosis, healthcare, and reporting, not an increase in the real incidence of the disease. When the Turkish literature was reviewed between 1915 and 1963 years, seropositivity of brucellosis was found as 9\%, approximately (26). In 1937, Celik found brucellosis in 2.6\% (27). In 1943, Golem found brucellosis in 5.9\% (28). In 1957, Akyay and Gursel found brucellosis in 4.3\% in Eskisehir Province in Central Turkey (29). In 1990, Cetin et al. (30) found active brucellosis in $1.8 \%$ in different major cities throughout Turkey. The highest level of seroprevalence observed among healthy individuals was 3.6\% in Diyarbak1r, which is in eastern Turkey (30).

Direct contact with livestock is a well-documented source of infection. Infection may occur through cuts and abrasions on the skin, via the conjunctiva and by inhalation. These routes of infection are important for farmers, veterinarians, and butchers, who are all at increased risk of infection through

Table 3. Seroprevalence of Brucella antibodies according to the livestocks' location and antibody titers

\begin{tabular}{lcccc}
\hline & + & ++ & +++ & Total \\
& $(\mathrm{n})$ & $(\mathrm{n})$ & $(\mathrm{n})$ & $(\mathrm{n})$ \\
\hline Aralık & 6 & 2 & 4 & 12 \\
Tuzluca & 3 & 2 & 1 & 6 \\
Doğubeyazıt & 8 & 3 & 0 & 11 \\
Karakoyunlu & 0 & 0 & 0 & 0 \\
Kağ1zman & 5 & 3 & 4 & 12 \\
Iğdır Center & 2 & 0 & 0 & 2 \\
\hline Total & 24 & 10 & 9 & 43 \\
\hline (n= number of livestock) & & &
\end{tabular}

Table 4. Seroprevalence of Brucella antibodies according to the livestocks' species and location

\begin{tabular}{|c|c|c|c|c|}
\hline & $\begin{array}{l}\text { Sheep } \\
\text { and goat } \\
\text { (n) }\end{array}$ & $\begin{array}{c}\text { Cattle } \\
\text { (n) }\end{array}$ & $\begin{array}{l}\text { Total } \\
\text { (n) }\end{array}$ & $\mathrm{p}$ value \\
\hline Aralik & 10 & 2 & 12 & \\
\hline Tuzluca & 4 & 2 & 6 & \\
\hline Doğubeyazıt & 11 & 0 & 11 & \\
\hline Karakoyunlu & 0 & 0 & 0 & $\mathrm{p}=0.032$ \\
\hline Kağ1zman & 3 & 9 & 12 & \\
\hline Iğdır Center & 0 & 2 & 2 & \\
\hline Total & 28 & 15 & 43 & \\
\hline
\end{tabular}

( $\mathrm{n}=$ number of livestock $)$ 
their contact with animals and animal products. A different seroprevalence study was carried out on occupational risk groups consisting of veterinarians and veterinary assistants, slaughterhouse workers, and controls in Kocaeli, a city in northwest Turkey and the researchers found brucellosis seroprevalence of $4.8 \%$ in the risk groups (17). In our study, we found seroprevalence of brucellosis as $6.7 \%$ in whole study group. The seroprevalence in communities in the provinces of northeast Turkey was lower than in the provinces in the other regions, and we attributed this to the vaccination of livestock in the year preceding the survey.

As livestock herders, all of the household members had regular and repeated contact with livestock. Potentially high-risk interactions with livestock included home slaughter of multiple livestock species and hand milking of cattle, sheep and goats $(8,9)$. Generally adults were involved in livestock slaughter with men involved in the killing, skinning and deboning of the animals and women in the cleaning and preparing the gastrointestinal tract and internal organs. Both adults and children were observed milking cattle, sheep and goats $(11,13)$. In our study, seroprevalence of Brucellosis was found as $11.5 \%$ in male subjects and $5.4 \%$ in female subjects. There were no significant differences between the genders. The questionnaire did not include specific information on human exposure to livestock placentas, uterine fluid or aborted material.

Animal brucellosis was a serious problem in both state and private farms. A serological study mainly on sheep and goats in state farms was conducted and showed $2.6 \%$ reactors. The clear relationship between infected animals and humans was shown in a report in 1957; a herd in Eskisehir suffering acute brucellosis showed 11\% reactors, with 23\% of workers testing positive (29). In our current study, seroprevalence of Brucellosis was found as $26.92 \%$ in sheep and goat and $17.65 \%$ in cattle.

Seroprevalence of Brucellosis in sheep and goats was 1.53 fold higher than the cattles. There was a significantly higher seroprevalence of brucellosis among sheep and goats compared to the cattles $(\mathrm{p}<0.05)$. Of greater concern in this population was the high percent of interviewees who reported consuming raw cow's milk and preparing dairy products with raw milk. It is probable that the habits of the entire household would reflect the actions of the head of household in terms of raw milk consumption and that all members of the household would consume dairy products produced from the raw milk $(8,10)$. Although milk is routinely boiled immediately after collection these responses indicate that there is the potential for a significant level of human brucellosis exposure through the consumption of raw milk and dairy products in this population $(11,12)$.

Although brucellosis has been eradicated from several developed countries, it still continues to be a major public health problem in many regions of the world. There are many reasons why brucellosis remains endemic in Turkey $(17,19)$. Uncontrolled movements of livestock herds and flocks, geopolitical situation with endemic brucellosis in surrounding countries and political instability are main reasons of endemic brucellosis in Turkey. Inadequate veterinary support services and husbandry practices trigger the spread of infection in Turkey $(18,19,22)$. Traditional use of raw milk products and following close contact with infected animals occur permanence of human cases $(8,17$, 18). A distinct reduction in the levels of animal and human brucellosis had observed after the initiation of the national brucellosis control and eradication plan in 1984 and the new plan that was initiated in 2009 will continue to make progress (17).

The prevalence of brucellosis-seropositive cattle herds in I $\breve{g} d ı r$, Turkey, is undoubtedly associated with livestock production losses and probably associated with the occurrence of clinical signs and symptoms suggestive of brucellosis reported by the humans in the region (19). Although this study represents data from only a small portion of Turkey's livestock population there is no reason to believe that the occurrence of brucellosis in cattle is restricted to this study region. In any disease eradication and control program, strategies have to be made on the basis of the information available (17). We thought that, in national brucellosis control and eradication program, decisions have to be made on the basis of the information available. Therefore, this study may lead the new strategies for the national brucellosis control and eradication program in Igdir Province and surrounding regions.

Acknowledgment; The study was supported by the Iğdır University Scientific Research Foundation (Project No: 2012-SAB-B02).

Financial Disclosure; All authors declare that they have no conflict of interest. 


\section{References}

1. Boschiroli ML, Foulongne V, O'Callaghan D. Brucellosis: a worldwide zoonosis. Curr Opin Microbiol 2001; 4: 58-64.

2. Sauret JM, Vilissova N. Human brucellosis. J Am Board Fam Pract 2002; 15: 401-406.

3. Garin-Bastuji B, Blasco JM, Grayon M, Verger JM. Brucella melitensis infection in sheep: present and future. Vet Res 1998; 29: 255-274.

4. Corbel MJ. Brucellosis: an overview. Emerg Infect Dis 1997; 3: 213-221.

5. Seleem MN, Boyle SM, Sriranganathan N. Brucellosis: a re-emerging zoonosis. Vet Microbiol 2010; 140: 392-398.

6. Mantur BG, Amarnath SK. Brucellosis in-a review. J Biosci 2008; 539-547.

7. Franco MP, Mulder M, Gilman RH, Smits HL. Human brucellosis. Lancet Infect Dis 2007; 7: 775786.

8. Gamazo C, Lecároz MC, Prior S, et al. Chemical and biological factors in the control of Brucella and brucellosis. Curr Drug Deliv 2006; 3: 359-365.

9. Cutler SJ, Whatmore AM, Commander NJ. Brucellosis--new aspects of an old disease. J Appl Microbiol 2005; 98: 1270-1281.

10. Whatmore AM. Current understanding of the genetic diversity of Brucella, an expanding genus of zoonotic pathogens. Infect Genet Evol 2009; 9: 1168-1184.

11. Meng XJ, Lindsay DS, Sriranganathan N. Wild boars as sources for infectious diseases in livestock and humans. Philos Trans R Soc Lond B Biol Sci 2009; 364: 2697-2707.

12. McGiven JA. New developments in the immunodiagnosis of brucellosis in livestock and wildlife. Rev Sci Tech 2013; 32: 163-176.

13. Blasco JM, Molina-Flores B. Control and eradication of Brucella melitensis infection in sheep and goats. Vet Clin North Am Food Anim Pract 2011; 27: 95104.

14. Atluri VL, Xavier MN, de Jong MF, den Hartigh AB, Tsolis RM. Interactions of the human pathogenic Brucella species with their hosts. Annu Rev Microbiol 2011; 65: 523-541.

15. Ulu-Kilic A, Metan G, Alp E. Clinical presentations and diagnosis of brucellosis. Recent Pat Antiinfect Drug Discov 2013; 8: 34-41.
16. Gao G, Wang Y, Chen Z, Xu X, Xu J. Brucella virulence mechanisms and implications in novel vaccines and drugs. Crit Rev Eukaryot Gene Expr 2013; 23: 49-64.

17. Yumuk Z, O'Callaghan D. Brucellosis in Turkey -- an overview. Int J Infect Dis 2012; 16: 228-235.

18. Karadeniz N, Tiril A, Baylan E. Wetland management in Turkey: Problems, achievements and perspectives. Afr J Agr Res 2009; 4: 1106-1119.

19. Arvas G, Akkoyunlu Y, Berktas M, Kaya B, Aslan T. The Prevalence of Brucellosis in Adults in Northeastern Region of Turkey. Jundishapur J Microbiol 2013; 6: 262-264.

20. Young EJ. Serologic diagnosis of human brucellosis: analysis of 214 cases by agglutination tests and review of the literature. Rev Infect Dis 1991; 13: 359-372.

21. Al Dahouk S, Tomaso H, Nöckler K, Neubauer H, Frangoulidis D. Laboratory-based diagnosis of brucellosis--a review of the literature. Part I: Techniques for direct detection and identification of Brucella spp. Clin Lab 2003; 49: 487-505.

22. Kiliç S, Ivanov IN, Durmaz R, et al. Multiple-locus variable-number tandem-repeat analysis genotyping of human Brucella isolates from Turkey. J Clin Microbiol 2011; 49: 3276-3283.

23. Refai M. Incidence and control of brucellosis in the Near East region. Vet Microbiol 2002; 90: 81-110.

24. Darwish M, Benkirane A. Field investigations of brucellosis in cattle and small ruminants in Syria, 1990-1996. Rev Sci Tech 2001; 20: 769-775.

25. Simsek F, Yildirmak MT, Gedik H, Kantürk A, Iris EN. Pulmonary involvement of Brucellosis: a report of six cases. Afr Health Sci 11 Suppl 1: 2011; 112116.

26. Doguer M, Yilmaz S. Brucellosis in Turkey. Etlik Vet Bakt Enst Derg 1963; 2: 1-20.

27. Celik O. A case of abortus. Turk Tip Cem Mecmuasi 1937; 3: 14-16.

28. Golem SB. The situation of brucellosis in Turkey. Turk Hij Tec Biyol Derg 1949; 9: 32-63.

29. Akyay N, Gursel A. An outbreak of brucellosis and brucellosis in Turkey. Turk Hij Tec Biyol Derg 1957; 7: 208-215.

30. Cetin ET, Coral B, Bilgiy A, et al. Incidence of human brucellosis in Turkey. Doga $\operatorname{Tr} \mathrm{J}$ Medical Sciences 1990; 14: 324-334. 